\title{
Research on Quality Education and Innovative Talents Training Mode in Colleges and Universities
}

\author{
Shi Yong \\ School of Information \& Control engineering \\ Shenyang Jianzhu University \\ Shenyang, China \\ Tao Ning \\ School of Information \& Control engineering \\ Shenyang Jianzhu University \\ Shenyang, China
}

\author{
Xu Chong \\ School of Information \& Control engineering \\ Shenyang Jianzhu University \\ Shenyang, China
}

\begin{abstract}
With the reform of education system in China, quality education and cultivation of innovative talents have become an important direction of education in our country. With innovation consciousness and innovation ability of high quality talent is the country's need, the University in such a large environment, must continue to deepen reform, quality oriented education concept as the direction, continue to promote the reform of quality education, training innovative talents. This paper is to promote the development of quality education in Colleges and universities through the exploration of quality education and innovative talents training mode.
\end{abstract}

Keywords-Quality Education; University; Innovative Talents; Training Mode

\section{INTRODUCTION}

Quality education is a new education idea, it is outstanding to the students' overall quality and ability of the training, from the thought to the skills to get a comprehensive promotion, in this era of knowledge economy, quality education has become the focus of educational reform research object. Through the reform of the education system, the reform of the exam oriented education, and the development of quality education. University is an important place for the cultivation of talents in our country, but also the practice of scientific and technological innovation, so the quality education in Colleges and universities can be realized, the future of education in our country, but also related to the rise and fall of the country. Only through the university education to create a number of innovative talents with the times, can we continue to promote the development of our society and the progress of science and technology, the great rejuvenation of the Chinese nation, so that the quality of education and innovative talents training mode is essential.

\section{PRoblems IN Quality EdUCATION AND CREative TALENTS CULTIVATION OF COLLEGES AND UNIVERSITIES IN CHINA}

\section{A. Management Mode of the University Needs to be Improved}

School management is a very big one, in order to realize the transformation of quality education, must continue to cooperate with the management, school management is the basis for the development of education means, quality education must be based on the management of the function and value. However, due to the existence of the traditional school management mode, the new school management model has a huge impact, school administrators must withstand this part of the pressure, and constantly deepen reform, so as to find suitable for the development of quality education new model.

\section{B. University Curriculum System to be Optimized}

Curriculum is the center of teaching, only more suitable for quality education curriculum arrangement, in order to promote the development of quality education and innovative personnel training. In terms of the traditional curriculum, it is a discipline as the center, although the existing model has a certain change, there is an elective course, $\mathrm{Xu}$ Sheng according to their own preferences to choose the favorite courses, and constantly improve their comprehensive quality. However, in the actual teaching, the elective course is not enough attention, on the one hand, in the allocation of teaching resources, students in the elective courses cannot go to school to learn something. On the other hand, the teaching mode is still based on knowledge. The practical application ability of knowledge is low. The students can only focus on the classroom, resulting in the rigidity of students learning mode. The disadvantages of the examination oriented education are 
very obvious, which is very unfavorable to the cultivation of students' innovation ability.

On the other hand, there are some problems in the curriculum, which are more attention to the professional skills, while some of the students to improve the ideological quality and emotional training course is less. This also does not accord with the requirements of quality education, to know the use of this model to cultivate students, professional skills, but there are more or less problems in the ideological and moral education, such as the talent into the society is difficult to adapt to social development, it is possible to show strong individualism, while the lack of innovation and awareness, and not social needs.

On the one hand, it is the lack of the curriculum and the development of the times, we know that the development of modern society is very fast, and it is difficult to adapt to the development of the society. For example, in the elective course, to fully reflect the times, let the students learn the most authentic side of the society, while the introduction of elective courses to highlight the authenticity, to provide a good basis for students to avoid the blindness of students, in some special courses practical operation, as far as possible to allow students to accept some social skills, to avoid the phenomenon of students learning skills and social separation, resulting in the loss of competitive advantage into society.

\section{The Construction of the Teachers in Colleges and Universities Needs to be Improved}

Teachers are the main body of the teaching activities, so that the quality of teachers directly determines the quality of teaching, and now most of the teachers in Colleges and universities are new teachers, some of the older teachers are engaged in research work, while the establishment of teachers' training mechanism is not perfect, resulting in Teachers' teaching level is not up. The main cause of this problem is the lack of attention to the construction of teachers in Colleges and universities. Quality education highlights the improvement of students' comprehensive ability, while some teachers pay attention to the teaching of professional skills and problem-solving skills, while ignoring the students' Ideological and moral education, in the process of communication with students in the process of rough and uneven, teacher-student relationship is not harmonious; Some teachers in itself has a problem, people can't, lack of sense of responsibility, in the eyes of poor students. These are strict total hinders the development of quality-oriented education, teachers to continue to implement quality education, and even some teachers will be counterproductive to some extent, the development of quality education is not easy.

\section{THINKING ON THE CULTIVATION OF INNOVATIVE TALENTS IN COLLEGES AND UNIVERSITIES}

\section{A. Colleges are Beneficial Places to Cultivate Innovative Talents}

University education focusing on college students to enhance their skills and perfect personality, and enhance the overall capability of university research is also important to place many major research university research are done indoors, especially in many of the Nobel abroad
Prize winner from college are ongoing self-improvement. On the current definition of education in our country for university education as higher education, aims to develop a high level of talent, both in the country or in the economic policy of support are great, community colleges and universities out for talent is also more popular.

\section{B. Innovation Can Stimulate People's Potentials}

Development of human society requires constant innovation, so they need innovative talents, thinking from the philosophical point of view, human consciousness is the source of creation, the development of education as a basic form of intelligence, improve people's comprehensive ability, the requirements for innovation capacity is rising, society in order to progress, we must rely on the potential of innovation and continue to inspire people, to create more new things, foster innovation people can be said to be the duty of the fundamental task of education is also education. Innovative talents not only need to have a unique ability to innovate but also have enough scientific knowledge and a wealth of cultural enrichment, these are necessary, he can find from everyday life, and create by imagination, the first requirement is to have a pair of discovery glasses, thus cultivating innovative talents to combine the world of this diverse culture, fully stimulate the human potential, to know to make unlimited human potential, and only continue to inspire, will have a higher increase.

\section{The Cultivation of Innovative Talents Needs System as the Guarantee}

For the training, a sound system is the guarantee, indepth analysis of the forms of education, the reason is the lack of a suitable quality education and innovative personnel training system, on foreign education, foreign higher education models and China has very different, its outstanding students free, students are free to choose according to their own hobby development, fewer restrictions for students, a greater degree of freedom of students, at the same time focus on improving all aspects of the student's own ability, and not focus on a single the cultural achievements, and our education, college entrance examination this one stepping stone, which is the fundamental education in China, quality education for our country, our education reform policy clearly states the importance of reform, the various colleges and universities to actively respond national call, further deepen education reform, the creation of a strong guarantee for China's educational development quality.

\section{ESTABLISH QUALITY EDUCATION AND TALENT Cultivation Mode in ChinA’s COLLEGES}

\section{A. Highlight the Concept of Cultivating Innovative Talents}

Idea innovative training model is mainly reflected in two aspects, teaching philosophy and work ethic of students. The teaching process is the core of education, so in order to improve the quality of education we must continue with the new teaching philosophy, the traditional concept of education into a single innovative concept of integrated education, focusing on all-round development of students, especially innovation capability The development, 
to establish the concept of quality school education development, improve the quality of quality education, and not just focus on form, actively explore innovation in content quality education, formal aspects, the development of new objectives for the educational development of our country, but also pay attention to idea, innovation theory and practice of combining the culture out in practice, a focus on teaching model theory is impossible to cultivate innovative talents, enhance students' enthusiasm in teaching, outstanding student body concept, so that students focus to learn knowledge, rather than being forced to accept the knowledge. Students work as an important part of quality education, we want to highlight their characteristics, we know that students work for the students communication skills and social values play an important role in the students' work ethic, not just stay on the level of disciplining students, not The student work is seen as a tool for management students, to rise to the level of education, management education play a prominent effect, for the development of quality education played a good supporting role.

\section{B. Pay Attention to Improving College Students' Overall Quality}

The salient features of quality education are emphasized to enhance students 'comprehensive ability to develop simulation training related to quality development in the new training model is necessary, it can help students experience the designer concept, exercise students' ability to cope with problems to enhance students' overall quality. Practical ability and creativity of college students are promoted to get exercise in practice, so there must be a special exercise programs for college students, so that students can visit the community feel the atmosphere, theory and practice of combining community, the ability of students observant, a pair of problems found in real life eyes, the only way to innovate. In the specific arrangements can learn from foreign advanced teaching experience, combined with the features of the school, the ability to exercise all aspects of college students as the goal, around the social services, thought to enhance the quality, content physical and mental development, professional skills development to expand comprehensive upgrade all aspects of student ability.

\section{Improve Quality Education Evaluation System}

Perfect evaluation system development is inseparable from Quality Education Evaluation System for College Education can guide and promote the comprehensive development of students, the quality of education at the same time be able to help find potential problems, so that the quality of education more responsive to the development of the school. Evaluation of the evaluation system have diverse content, not just for students in class evaluation, but also summarize the evaluation of students from other aspects of development, so that a student's evaluation will be more comprehensive, quality education is fundamental to development, through the evaluation system of students overall ability to make a generalization on the one hand to give students an understanding of their capabilities, to facilitate students in the course of employment weaknesses, play to their advantages, but also motivate students to learn, to make up for their own lack of evaluation system evaluation on innovative ability, reflecting the emphasis on the ability of universities to innovation is the key point of Creative Talent.

\section{Strengthen Organization and System Requirements to Form Powerful Guarantee}

In terms of organization, universities should establish a new management concept, the establishment of new management goals, from the perspective of sound management mechanism organizations to form the leadership of the university hospital level of organization and management model, the quality of education for students as well as students' personal development plan proposed overall to facilitate the self-selection of students and enhance the overall capabilities. In the system, the development of quality education in line with the innovative training model to adapt to the system, to change the traditional concept of system constraints, the new system service-oriented philosophy, highlighting the importance of the formation of the service, and constantly enhance the level of service, so that the system becomes development of quality education a powerful guarantee, through the development of policies and systems to form a stable mechanism to provide protection for quality education and innovative training model.

\section{CONCLUSION}

The development of quality education is an important direction of education reform in our country, the main place of personnel training in our country, facing the grim international situation, we must deepen the reform of education system, highlight the importance of quality education, and lay the foundation for the development of our country. In order to make clear the problems faced by the development of quality education in our country, we should pay more attention to the management mode, course system reform and the construction of teaching staff. It is important to establish quality education and innovative talents training mode.

\section{REFERENCES}

[1] Zhang Xvdong, Zhong Fuzu, Research into Quality Education at Colleges and Cultivating Innovative Talents $[\mathrm{J}]$. Education and Culture Forum, 2013,01:32-36.

[2] Huang Wei, Tang You, Tong Mingliang. Research on innovation and entrepreneurial talent cultivation mode of private universities based on regional economic development [J]. Journal of Heilongjiang Bayi Agricultural University,2013,02:92-94.

[3] Yang Xiaohui. Research on the cultivation of entrepreneurship education and innovative talents in Colleges and universities of China [J]. China higher education research, 2015,01:39-44.

[4] Jiang Hui, Ying Huiguang, Xu Xiaochang. Research Universities personalized innovative talents training mode $[\mathrm{J}]$. Journal of the National Institute of educational administration, 2015,03:27-31.

[5] Liu Hongning, Zhu Weifeng, Kang Shengli. A review on the literature review of the research on the training mode of innovative talents in Colleges and Universities [J]. Chinese Medicine Education, 2014,03:4-8.

[6] Zhang Jingjing. Innovation and transformation of humanistic quality education in Colleges and Universities under the background of innovative talents cultivation [J] China Light Industry Education, 2014,04:37-40.

[7] Chen Yan. Research on the cultivation mode of innovative talents in Colleges and Universities Based on the scientific development concept[J]. Jiangxi Social Science, 2011,11:222-225. 